\title{
A new species of Austrodecus Hodgson, 1907 (Arthropoda, Pycnogonida, Austrodecidae) from the Southwest Indian Ridge
}

\author{
Jian-Jia Wang ${ }^{1, \dagger}$, Ding-Yong Huang ${ }^{1, \neq}$, Rong-Cheng Lin ${ }^{1, \S}$, Xin-Qing Zheng ${ }^{1,1}$ \\ I Third Institute of Oceanography, SOA, Daxue Road No.178, Xiamen 361005, P.R. China \\ † http://zoobank.org/C20B95E3-8D74-4AB5-B7E4-FC9C744FE141 \\ ¥ http://zoobank.org/2712DC19-7B6B-4BF3-94DA-9FEB603E4643 \\ § http://zoobank.org/9828DDFB-5B68-4C55-8732-D4EFECAB3EAO \\ | http://zoobank.org/EFDC4026-8D02-499E-B543-144F72575291
}

Corresponding author: Rong-Cheng Lin (rclinxm@189.cn)

Academic editor: Roger Bamber | Received 30 August 2013 | Accepted 1 November 2013 | Published 13 November 2013

http://zoobank.org/D08A5D8C-CB78-49FA-AC71-F6F83143A091

Citation: Wang J-J, Huang D-Y, Lin R-C, Zheng X-Q (2013) A new species of Austrodecus Hodgson, 1907 (Arthropoda, Pycnogonida, Austrodecidae) from the Southwest Indian Ridge. ZooKeys 349: 73-79. doi: 10.3897/zookeys.349.6170

\begin{abstract}
A new species of pycnogonid collected by the Chinese research vessel R/V Dayangyihao during cruises to the Southwest Indian Ridge in 2008 and 2009 is recorded. The new species, Austrodecus bamberi, is placed into the tristanense-section by the characters of 4-articled ovigers and present auxiliary claws and is distinguished from other species in this section by the number and length of tubercles on the first coxae.
\end{abstract}

\section{Keywords}

Southwest Indian Ridge, Pycnogonida, Austrodecus

Copyright Jian-Jia Wang et al. This is an open access article distributed under the terms of the Creative Commons Attribution License 3.0 (CC-BY), which permits unrestricted use, distribution, and reproduction in any medium, provided the original author and source are credited. 


\section{Introduction}

The genus Austrodecus Hodgson, 1907 counts 41 named species now (Bamber and El Nagar 2013), predominantly in the southern hemisphere or in the Antarctic and Sub-Antarctic localities. There are four species found in the northern hemisphere, A. tubiferum Stock, 1957 and $A$. palauense Child, 1983 from western pacific, $A$. conifer Stock, 1991 and $A$. (T.) aconaea (Hedgpeth \& McCain, 1971) from the northeastern side of Atlantic and the Pacific respectively. Stock (1957) placed the then known species into four sections based principally on the number of oviger articles and the presence or absence or state of development of the auxiliary claws. $\mathrm{He}$ identified these sections as the glaciale-section, the breciceps-section, the tristanensesection and the gordonae-section. Bamber and Thurston (1993) published a key to the known species of genus Austrodecus not including the species in the glaciale-section. Stock (1991) and Child (1994) founded subgenus Tubidecus and Microdecus based on oviger morphology and the position and shape of the cement gland tube respectively. Child's (1994) monograph provides the most comprehensive analysis of the genus to date and includs a key to the Antarctic and Sub-Antarctic species. Only two species have since been described: A. (Tubidecus) oferrecans Bamber, 2000 and A. childi Arango, 2003.

Six new hydrothermal fields and two water column hydrothermal anomalies were recorded along Southwest Indian Ridge (SWIR) during Legs 5-7 of the Chinese DY115-20 cruise on the R/V Dayangyihao from 2008 to 2009 (Tao et al. 2009). A series of research studies were undertaken, including benthic surveying, water sampling, and grabbing for biological specimens and geological material along the $48-54^{\circ} \mathrm{E}$ segment of SWIR. At station DY115-20VII-TVG02, close to the new hydrothermal field $\left(51.732^{\circ} \mathrm{E}, 37.466^{\circ} \mathrm{S}, 1,595 \mathrm{~m}\right)$ (Tao et al. 2009), one specimen of Pycnogonida obviously belonged to the genus Austrodecus was collected. After checking the known species list, it is conformed as a new species and described below.

\section{Material and methods}

This specimen was collected by a deep sea TV-grab and sorted from the other benthic fauna and sediment from Station DY115-20VII-TVG02. Type material is conserved at the Third Institute of Oceanography, SOA, China. Specimens were drawn using a camera lucida. Measurements are made axially, dorsally for the trunk, laterally for the palp, proboscis and leg. 


\section{Systematics}

Class Pycnogonida Latreille, 1810

Order Pantopoda Gerstäcker, 1863

Suborder Stiripasterida Fry, 1978

Family Austrodecidae Stock, 1954

Genus Austrodecus Hodgson, 1907

Austrodecus bamberi sp. n.

http://zoobank.org/2DEE9D65-4F7A-487C-8BA6-1EFE8EB1EE7E

http://species-id.net/wiki/Austrodecus_bamberi

Figs 1,2

Material examined. one male, holotype (TVG0201), DY115-20VII Station 2, SWI, $37.4654^{\circ} \mathrm{S}, 51.7213^{\circ} \mathrm{E}, 1307 \mathrm{~m}$ depth, TVG, 4th February 2009.

Diagnosis. Trunk with four dorsomedian tubercles, moderately tall. All first coxae with slender dorsodistal tubercles, from anterior to posterior in formula 2: 2: 2: 1 . The anterior tubercle on the first coxa of first leg is shorter than others. Cement gland dome-shaped, placed dorsally at centre of femur, on all legs. Legs with long dorsodistal spine on each major article.

Description of the holotype (male). Size moderately large for genus; leg span $6.68 \mathrm{~mm}$. Trunk slender, with many tiny papillae, completely segmented, dorsal segmentation lines raised, swollen, with four dorsomedian tubercles, moderately tall. Lateral processes separated by at least their own diameters, with tiny dorsodistal papillae. Ocular tubercle long, directed obliquely forward, slender, armed with short tubercles, without obvious eyes, tip weakly bifurcate. Proboscis typical, slender, longer than trunk length, distal part down-curved, with about 40 annulations, base swollen. Abdomen with tiny dorsal papillae, horizontal, extending to third coxae of fourth pair of legs.

Palps six-articled. First article broad, without spines or setae. Second article longest, with few short seta and spines. Articulation lines between second, third and fourth articles indistinct. Second to fourth articles with thorn-like tubercles on dorsal surfaces. Fourth article almost half length of second article, bearing four inwardly-curved spines, armed with seta. Distal two articles short, terminal article synaxial to penultimate article, both armed with fields of ventral and distal setae mostly little longer than their article diameter.

Ovigers small, four-articled. First to third articles with 1 or 2 setae. Fourth article longest, bearing several ventral and distal setae.

Legs slender, with tiny papillae and thorn-like tubercles. Major articles with long dorsodistal spine. First coxae with tall slender tubercles bearing short thorn-like tubercles and short seta, from anterior to posterior in formula 2: 2: 2: 1 . Anterior tubercle on first coxa of first leg shorter than others. Second coxae longest, distally swollen, with short ventral seta and distal spines. Third coxae short, with low tubercle. Femur the longest article, with few short setae and spines. Cement glands dome-shaped, endal at 


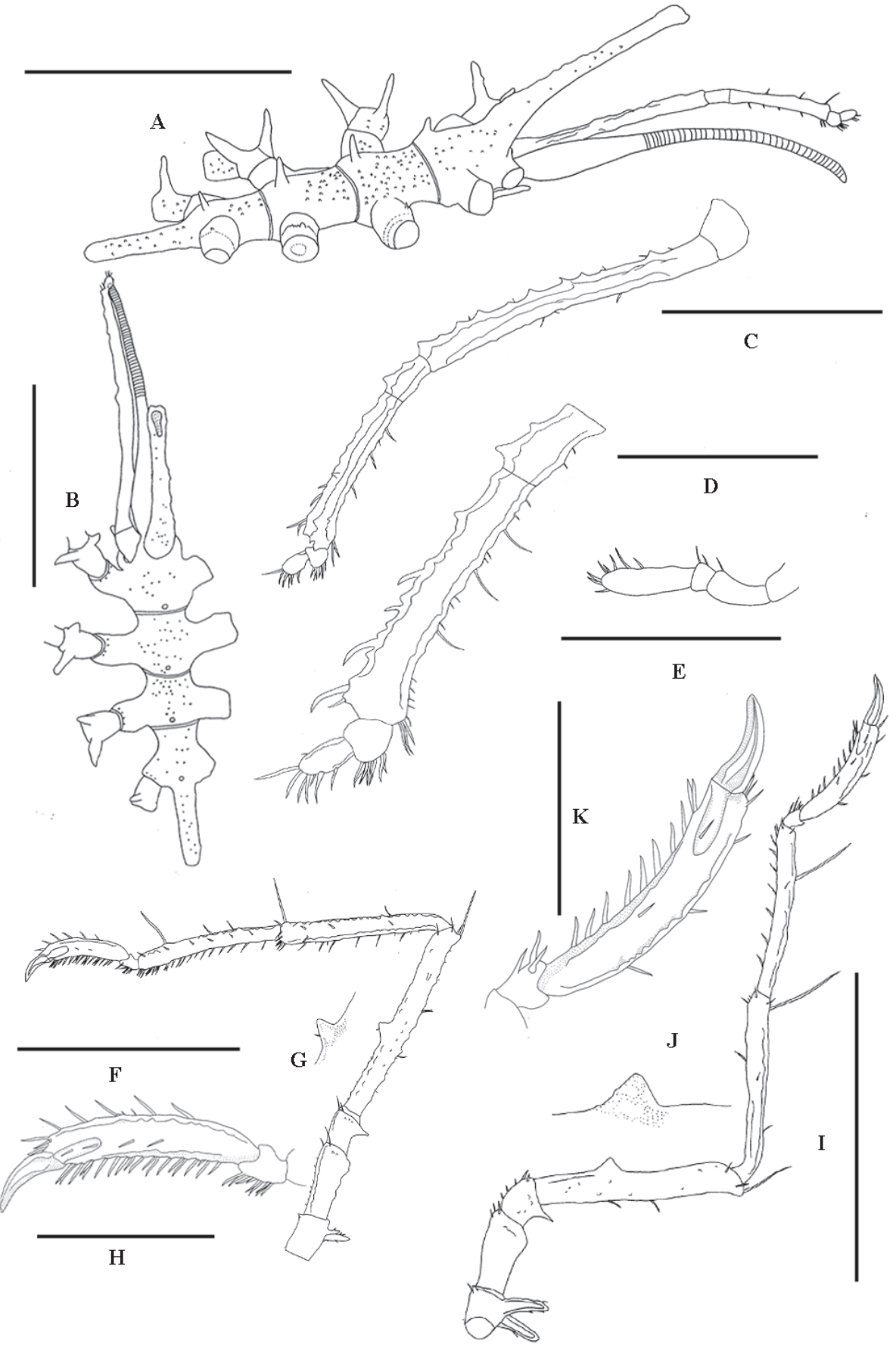

Figure I. Austrodecus bamberi sp. n., TVG0201, male holotype: A trunk, lateral view B trunk, dorsal view $\mathbf{C}$ palp $\mathbf{D}$ terminal articles of palp, enlarged $\mathbf{E}$ oviger $\mathbf{F}$ leg $1 \mathbf{G}$ cement gland tube of leg 1, enlarged $\mathbf{H}$ tarsus, propodus, and claws of leg 1, enlarged $\mathbf{I}$ leg $3 \mathbf{J}$ cement gland tube of leg 3, enlarged $\mathbf{K}$ propodus, and claws of leg 3, enlarged. Scale bars (A, B, F, I= $1.0 \mathrm{~mm}$; C= $0.5 \mathrm{~mm}$; D, E, H, K= $0.25 \mathrm{~mm}$ ). 


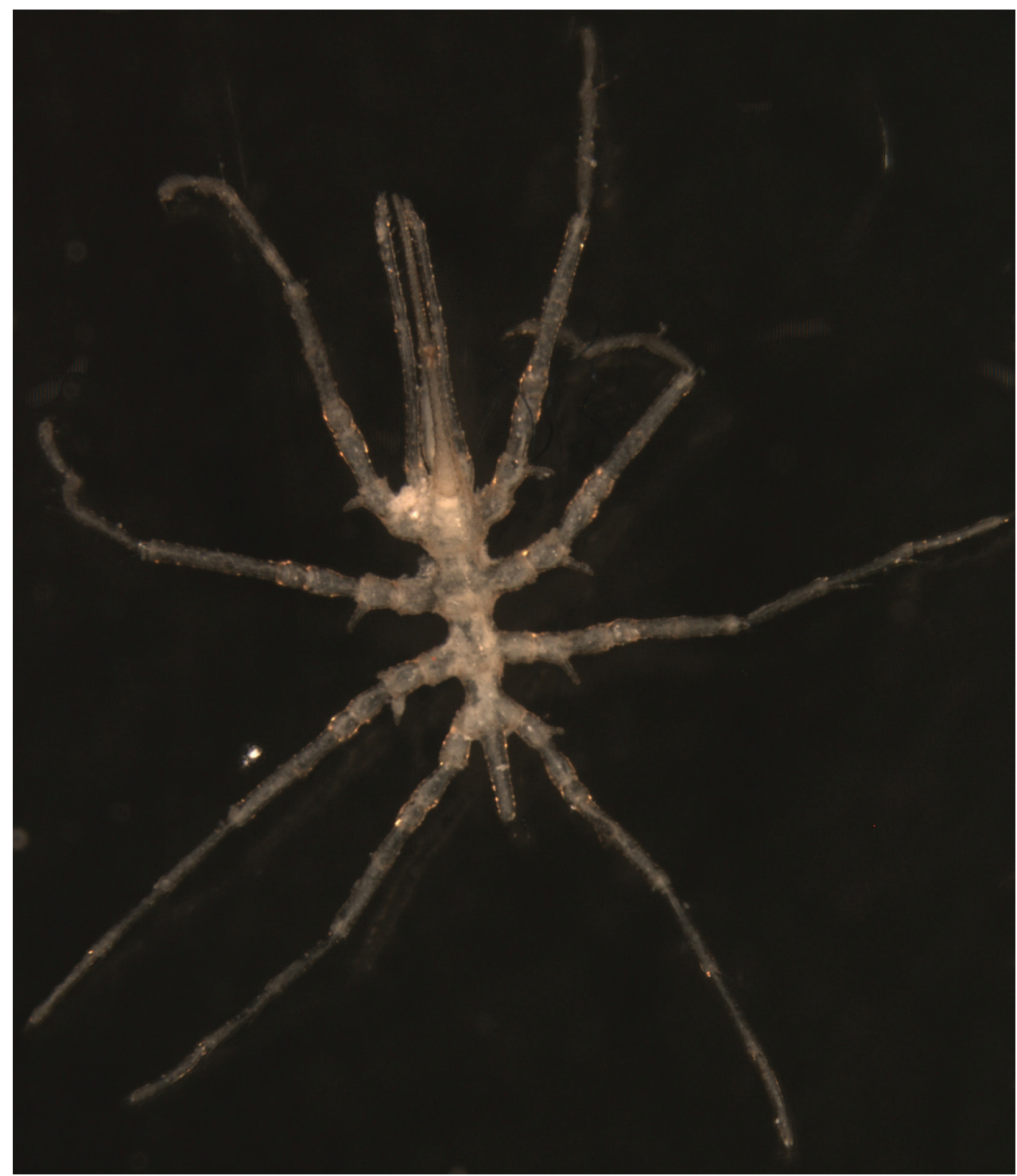

Figure 2. Austrodecus bamberi sp. n. male holotype. Photograph from dorsal view.

centre of femur, on all legs. Spines on tibiae, tarsus and propodus decreasing in number from anterior to posterior legs. First tibiae longer than second, with fewer ventral spines. Tarsus with ventral spines, 9 on first, 7 on second, 3 on third and fourth pair. Propodus moderately curved, with 3 distal spines and 3-5 long dorsal spines (5 on first, 4 on second, 3 on third and fourth), single row of sole spines (19 on first, 13 on second, 10 on third and fourth). Main claw strong, two tiny auxiliary claws little longer than diameter of main claw.

Female and juvenile are unknown. 
Measurements of holotype in mm: Trunk length (from chelifore insertion to tip of 4th lateral processes), 1.29; width across 2 nd lateral processes, 0.71 ; proboscis length, 1.35; ocular tubercle, 0.88 ; abdomen, 0.47 .

Length of palp articles 1 to 6 respectively: $0.06 ; 0.73 ; 0.11 ; 0.40 ; 0.04 ; 0.06$.

Length of oviger articles 1 to 4 respectively: $0.04 ; 0.07 ; 0.02 ; 0.11$.

Third leg, coxa $1,0.15$; coxa 2, 0.23; coxa 3, 0.11; femur, 0.67; tibia 1, 0.56; tibia 2, 0.54; tarsus, 0.04; propodus, 0.39; claw, 0.12; auxiliary claw, 0.036 .

Measurements of first leg: coxa 1, 0.14; coxa 2, 0.28; coxa 3, 0.19; femur, 0.80; tibia 1, 0.76; tibia 2, 0.65; tarsus, 0.06; propodus, 0.36; claw, 0.12; auxiliary claw, 0.029 .

Etymology. This species is dedicated to Dr. Roger N. Bamber in recognition of his excellent work on the all world's Pycnogonida.

Remarks. This species belongs to the A. tristanense section sensu Stock (1957) which is characterised by 4 -articled ovigers and the present of auxiliary claws. Four species are assigned to this section (A. tristanense Stock, 1955, A. goughense Stock, 1957, A. elegans Stock, 1957 and $A$. calvum Stock, 1991, see Child 1994). Three species possess mid-dorsal trunk tubercles. Of these, $A$. bamberi sp. n. is most like $A$. calvum and A. elegans with which it shares the widely-spaced lateral processes however A.calvum does not possess mid-dorsal processes and further differs in the ratio of the lateral tubercles. Using the keys provided by Bamber and Thurston (1993) and Child (1994) A. bamberi keys out to $A$. elegans but these species are readily distinguished by the number and length of tubercles on first coxae and the much lower mid-dorsal trunk tubercles of $A$. elegans.

Deep-sea pycnogonids occasionally occurred in the vicinity of hydrothermal vents and deep-sea ridges, however Sericosura is the only obligate vent-associated pycnogonid genus (Bamber 2009). Austrodecus bamberi was obtained on the top of ridge, close to the hydrothermal field but without evidence any obligate association. White sediment and a small amount of basalt accompanied the specimen in the TV-grab. The specimen was recovered by washing the sediment through a sieve. Corals attached to the basalt, gastropods and one squat lobster (Heteronida sp.) were also recovered from the same sample.

The sea floor appears to be predominantly composed of soft sediment.

\section{Acknowledgments}

We are grateful to Dr. Roger N. Bamber of ARTOO Marine Biology Consultants for his assistance. This work was supported by China Ocean Mineral Resources Research and Development Association Program (Grant No. DY125-11-E-03 \& DYXM-115-02-4-05), National Youth Science Fund (Grant No. 41206157) and the Scientific Research Foundation of Third Institute of Oceanography, SOA (Grant NO.2012008). 


\section{References}

Arango CP (2003) Sea spiders (Pycnogonida, Arthropoda) from the Great Barrier Reef, Australia: new species, new records and ecological annotations. Journal of Natural History 37 (22): 2723-2772. doi: 10.1080/00222930210158771

Bamber RN (2000) Pycnogonida: Pycnogonids from French cruises to New Caledonia, Fiji, Tahiti and the Marquesas. New records and new species. Mémoires du Muséum national d'histoire naturelle 184: 611-625.

Bamber RN (2009) Two new species of Sericosura Fry \& Hedgpeth, 1969 (Arthropoda: Pycnogonida: Ammotheidae), and a reassessment of the genus. Zootaxa 2140: 56-68.

Bamber RN, El Nagar A (Eds) (2013) PycnoBase: World Pycnogonida Database. http://www. marinespecies.org/pycnobase/ [accessed on 05 August 2013]

Bamber RN, Thurston MH (1993) Deep water pycnogonids of the Cape Verde slope. Journal Marine Biology Association UK 73: 837-837. doi: 10.1017/S0025315400034767

Child CA (1983) Pycnogonida of the Western Pacific Islands. II: Guam and the Palau Islands. Proceedings of the biological Society of Washington 96 (4): 698-714.

Child CA (1994) Antarctic and Subantarctic Pycnogonida: I, Ammotheidae and II, Austrodecidae. In: Cairns SD (Ed) Biology of the Antarctic Seas XXIII. Antarctic Research Series 63: 1-99.

Hedgpeth JW, McCain JC (1971) A review of the pycnogonid genus Pantopipetta (family Austrodecidae, emended) with the description of a new species. Biology of the Antarctic Seas 4: 217-229.

Hodgson TV (1907) Pycnogonida. National Antarctic Expedition 1901-1904. Natural History 3: $1-72$.

Stock JH (1955) Pycnogonida from the West Indies, Central America and the Pacific coast of North America. Papers from Dr. Th. Mortensen’s Pacific Expedition 1914-1916. Vidensk Medded Dansk Naturh Foren 117: 209-266.

Stock JH (1957) The pycnogonid family Austrodecidae. Beaufortia 6(68): 1-81.

Stock JH (1991) Deep-water Pycnogonida from the surroundings of New Caledonia. Résultats des Campagnes MUSORSTOM 8(4): 125-212.

Tao CH, Wu GH, Ni JY, Zhao H, Su X, Zhou N, Li J, Chen Y, Cui R, Deng X (2009) New hydrothermal fields found along the SWIR during the Legs 5-7 of the Chinese DY115-20 Expedition. AGU Fall Meeting Abstracts 1: 1150. 
